\title{
Rattlesnake Envenomation in a Venom-Naive Man With Significant Coagulopathy and Severe Oropharyngeal Edema Requiring Emergent Surgical Airway
}

\author{
Peter D. Drevets ${ }^{\mathrm{a}, \mathrm{d}}$, Lillie Tien ${ }^{\mathrm{a}}$, Richard J. LaCoursiere ${ }^{\mathrm{b}}$, \\ Todd E. Burgbacherc ${ }^{\mathrm{c}}$ Elizabeth D. Fox ${ }^{\mathrm{a}}$
}

\begin{abstract}
The majority of snakebite envenomation events in North America are attributed to rattlesnakes with pit-vipers responsible for nearly all envenomation events. Significant morbidity is associated with rattlesnake envenomation including local tissue destruction and coagulopathy. Severe oropharyngeal edema requiring emergent securing of airway has been reported in victims with no prior exposure to pit-vipers but is exceptionally rare. We present a case report of a venom-naive male in his early twenties who received a pit-viper bite to the right thumb, resulting in an anaphylactoid reaction complicated by severe oropharyngeal edema, coagulopathy, and persistent respiratory failure requiring prolonged ventilator support. This case highlights how anaphylactic and anaphylactoid reactions are nearly identical in presentation and may be associated with significant morbidity. Regardless of whether the underlying etiology is anaphylaxis or anaphylactoid, the management should focus on providing $\mathrm{CroFab}^{\circledR}$ early in the clinical course.
\end{abstract}

Keywords: Anaphylaxis; Anaphylactoid; Venom-induced consumptive coagulopathy; Thromboelastography; Crotalidae polyvalent immune Fab

\section{Introduction}

Approximately 5,000 snake envenomation events are reported

Manuscript submitted October 16, 2020, accepted October 24, 2020

Published online January 30, 2020

aDepartment of Surgery, Augusta University Medical Center, Augusta, GA, USA

bDepartment of Pharmacy, Augusta University Medical Center, Augusta, GA, USA

'Department of Emergency Medicine, Augusta University Medical Center, Augusta, GA, USA

${ }^{\mathrm{d} C}$ Corresponding Author: Peter D. Drevets, Department of Surgery, Medical College of Georgia at Augusta University, 1120 15th Street, Augusta, GA 30912, USA. Email: pdrevets@augusta.edu

doi: https://doi.org/10.14740/jcs426 annually in the United States with rattlesnakes being the most commonly implicated species [1, 2]. Bites predominantly occur in the southern United States during warmer weather with young, Caucasian males being the most commonly reported demographic [3]. Local tissue destruction occurs to varying degrees in nearly all victims and generally presents with swelling and erythema $[1,4]$. Systemic effects of pit-viper envenomation include anaphylaxis, shock, coagulopathy, and less commonly, respiratory failure [5-7]. Intubation is exceedingly rare as a direct result of rattlesnake envenomation [7]. Anaphylactoid reactions are virtually indistinguishable from anaphylactic reactions and have rarely been reported in venom-naive individuals $[8,9]$. We present a case of severe envenomation in a venom-naive 21-year-old male resulting in anaphylactoid reaction and life-threatening oropharyngeal edema requiring emergent surgical airway.

\section{Case Report}

A young male in his early twenties presented to a rural emergency department in the southeastern USA $30 \mathrm{~min}$ after suffering a snakebite to his right thumb at approximately $1,300 \mathrm{~h}$. in early June. Per patient report, the bite was unprovoked, and the offending animal appeared to be a rattlesnake. His past medical history consisted of substance abuse and hypertension and he had no prior exposure to snake venom.

On initial hospital presentation, the patient was anxious and complained of pain in the right hand which demonstrated blanching erythema and a single puncture wound on the dorsal aspect of the right thumb. Vital signs at time of intake were a blood pressure of 137/104 mm Hg, heart rate of 142 beats per min (BPM), and oxygen saturation of $100 \%$ on room air. Initial laboratory findings at presentation showed a hemoglobin $(\mathrm{Hgb})$ of $17 \mathrm{~g} / \mathrm{dL}$, hematocrit (Hct) of $51.7 \%$, and international normalized ratio (INR) of 0.9 . The local poison control center was notified immediately after patient arrival and advised administration of Crotalidae polyvalent immune $\mathrm{Fab}\left(\mathrm{CroFab}^{\circledR}\right)$; however, antivenom was not administered due to concern for anaphylactic reaction. This aspect of the case will be further discussed and expanded in the discussion.

The patient began vomiting and complained of dyspnea while also experiencing visible worsening swelling of the 


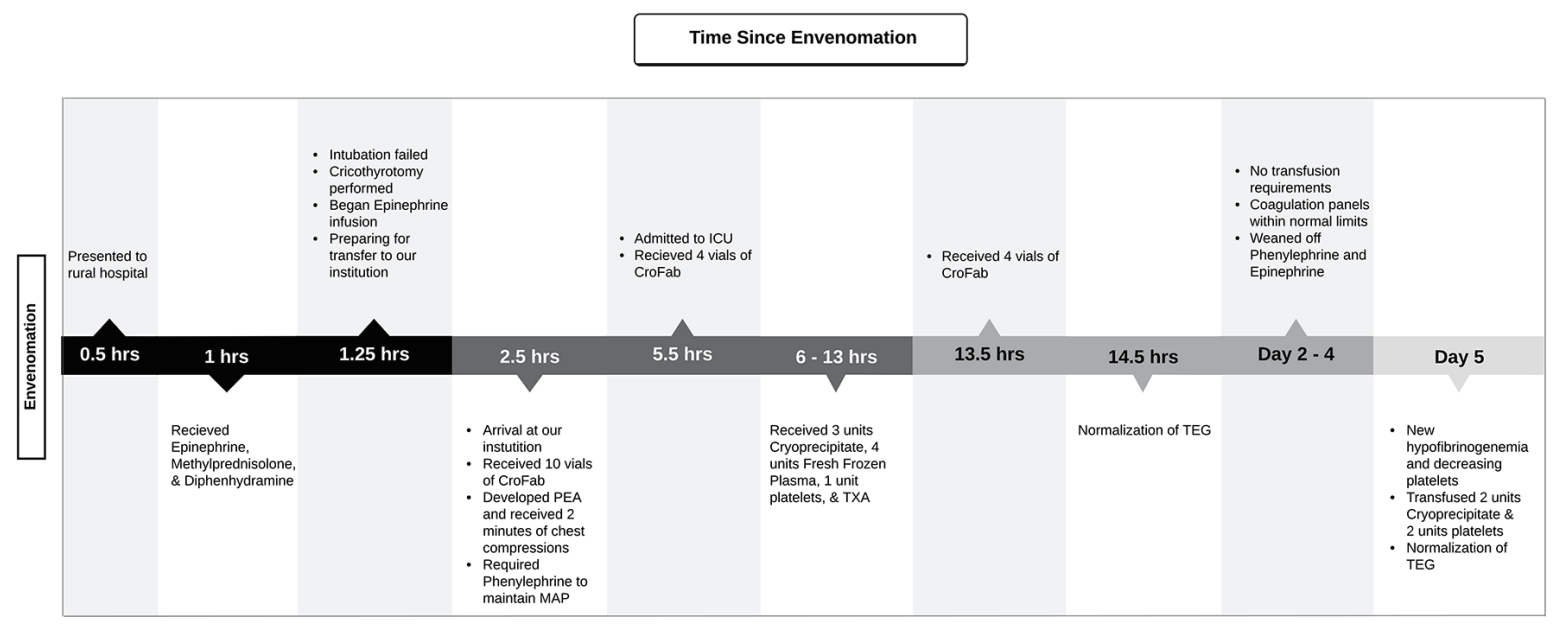

Figure 1. Timeline of the presentation of envenomation until normalized coagulation status. Timeline includes significant events in the patient's care and transfusion management. ICU: intensive care unit; PEA: pulseless electrical activity; MAP: mean arterial pressure; TXA: tranexamic acid; TEG: thromboelastography.

tongue and lips. $0.3 \mathrm{mg}$ of $1 \mathrm{mg} / \mathrm{mL}$ epinephrine solution was administered intramuscularly (IM) approximately 25 min after patient arrival. Of note, the patient weighed $91 \mathrm{~kg}$. Immediately following epinephrine administration, $250 \mathrm{mg}$ intravenous (IV) methylprednisolone, $50 \mathrm{mg}$ IV diphenhydramine, $50 \mathrm{mg}$ IV ranitidine, and $10 \mathrm{mg}$ albuterol jet nebulizer treatment were given with no alleviation of symptoms. $4 \mathrm{mg}$ ondansetron was administered for vomiting. The patient's oropharyngeal edema and dyspnea increased in severity and the patient soon became hypotensive. A continuous IV epinephrine infusion was begun at a rate of $2 \mu \mathrm{g} / \mathrm{kg} / \mathrm{min}$. Rapid sequence intubation was attempted, but unable to be performed due to oropharyngeal edema. A cricothyrotomy was then successfully performed (Fig. 1 for a timeline of events). The patient was then transferred by ground ambulance 24 miles to our tertiary care facility in eastern Georgia.

The patient arrived at our institution approximately $2.5 \mathrm{~h}$ after initial presentation. His vital signs were as follows: blood pressure of 94/52 mm Hg, heart rate of $150 \mathrm{BPM}$. Laboratory findings were as follows: $\mathrm{Hgb} 21.6 \mathrm{~g} / \mathrm{dL}$, Hct $64.5 \%$, platelets $401 \times 10^{3} / \mathrm{mm}^{3}$, and a white blood cell count of $21.6 \times 10^{3} /$ $\mathrm{mm}^{3}$. Repeated coagulation panels were drawn but were unable to be processed due to clotting of sample. The patient was also found to be profoundly acidotic with a $\mathrm{pH}$ of 7.05.

Ten vials of $\mathrm{CroFab}^{\circledR}$ had been prepared in anticipation of patient arrival and were administered immediately via infusion pump. Severe facial and oropharyngeal swelling were noted along with clotted blood in the oropharynx and around cricothyrotomy site. Swelling and discoloration was present on the right arm to the level of the axilla. Radial and ulnar pulses were readily palpable in the right extremity. Neurologic exam was limited due to administration of paralytics for intubation and transport. Approximately $20 \mathrm{~min}$ after patient arrival, pulseless electrical activity was noted on the monitor in conjunction with lack of femoral pulses. Two min of chest compressions were performed with obtainment of return of spontaneous circulation. Electrocardiogram obtained following the code event demonstrated sinus tachycardia without other abnormalities. Following the code event, there were decreased breath sounds noted on the right and the cricothyroidotomy tube was repositioned accordingly with positioning confirmed via bronchoscopy. The patient required two interventions with bronchoscopic suctioning of blood clot within $1 \mathrm{~h}$ of arrival.

The patient was then transferred to our intensive care unit and had continued gross bleeding of the oropharynx with new onset bleeding at the nares and IV puncture sites. By this time, there was significant suspicion for a systemic coagulopathic process causing diffuse clinical bleeding. Thromboelastographic assays (TEG) were sent to obtain rapid whole-picture status of the patient's coagulation status. The TEG results indicated a clinically significant coagulopathy and the patient was transfused accordingly (Table 1).

Successive doses of $\mathrm{CroFab}^{\circledR}$ were prepared at a strength of 4 vials $/ 250 \mathrm{~mL}$ normal saline and administered via infusion pump at 3-, 11-, and $17 \mathrm{~h}$ post admission. The coagulopathy was treated with three units of cryoprecipitate, four units of fresh frozen plasma (FFP), and one unit of platelets. The patient was administered a total of 22 vials of $\mathrm{CroFab}^{\circledR}$ during the first $24 \mathrm{~h}$ of admission with no subsequent re-administrations. Hydrocortisone $100 \mathrm{mg}$ IV was administered at a frequency of every $8 \mathrm{~h}$ for $48 \mathrm{~h}$ from time of admission. The patient's acidemia resolved with IV crystalloid resuscitation within 12 $\mathrm{h}$ of admission.

The patient required vasopressor support with phenylephrine and epinephrine infusions until day 3 in hospital due to intermittent but persistent hypotension. Phenylephrine infusion was discontinued on day 2 in hospital having been run at a rate of 0.1 to $1 \mu \mathrm{g} / \mathrm{kg} / \mathrm{min}$. Epinephrine infusion was required at a rate of 0.01 to $0.05 \mu \mathrm{g} / \mathrm{kg} / \mathrm{min}$ until discontinuation on day 3 in hospital. On day 3 in hospital, the patient underwent formalization of tracheostomy. Ventilatory support was required until hospital day ten and the patient was maintained on tracheostomy collar until day 12 in hospital. The hospital course was complicated by right sided poly-microbial pneumonia diagnosed on day 3 in hospital, which was empirically treated 


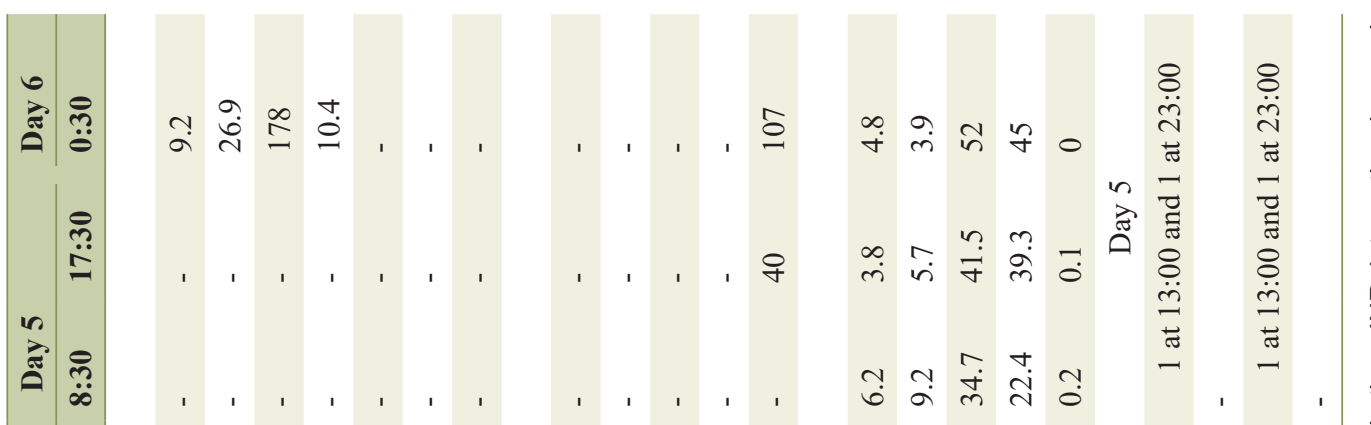

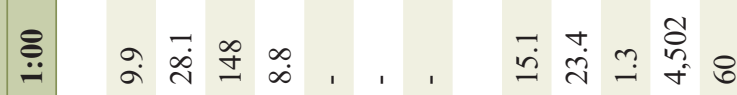

苛

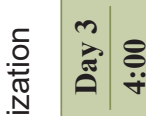

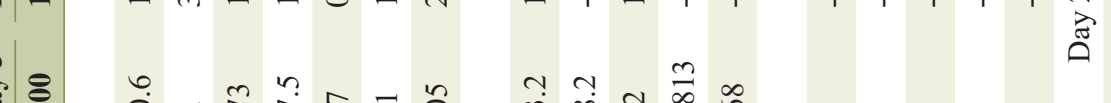

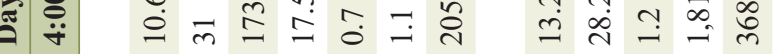

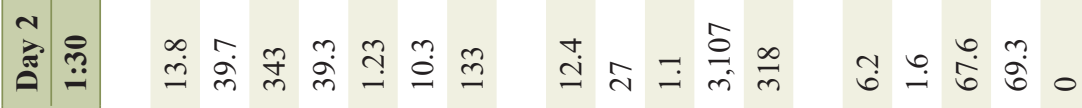

:

๖ํ.

in

$\stackrel{\oplus}{+}$

خ.

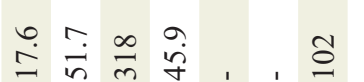

(5.

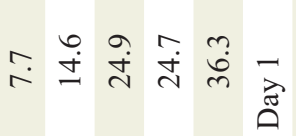

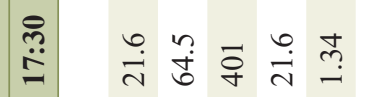

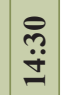

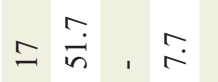

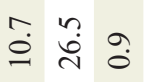


with vancomycin and cefepime.

The patient's hemoglobin and platelets began to downtrend on day 2 in hospital and by day 5 in hospital, the patient had a Hgb of $9.9 \mathrm{~g} / \mathrm{dL}$ from a Hgb of $13.8 \mathrm{~g} / \mathrm{dL}$ and a platelet count of $148 \times 10^{3} / \mathrm{mm}^{3}$ from a platelet count of $343 \times 10^{3} /$ $\mathrm{mm}^{3}$. His D-dimer was noted to have risen from $1,813 \mathrm{ng} / \mathrm{mL}$ on day 3 - 4 in hospital to $4,502 \mathrm{ng} / \mathrm{mL}$ on day 5 in hospital while his fibrinogen decreased from 368 to $60 \mathrm{mg} / \mathrm{dL}$. TEG assays were then sent and the patient was transfused two units of cryoprecipitate and two units of platelets, resulting in normalization of TEG and conventional coagulation panel. The patient was transferred to the general surgical ward on day 13 in hospital and discharged on day 14 in hospital.

\section{Discussion}

Severe anaphylactic reactions to rattlesnake venom are rare and generally require prior exposure, but anaphylactoid reactions may be observed in venom-naive patients [7-12]. Anaphylactic reactions are caused by pre-formed immunoglobulin $\mathrm{E}(\mathrm{IgE})$ antibodies that have been created in response to previous snake venom exposures. These pre-formed IgE antibodies then mount an amplified envenomation response to subsequent venom antigens, leading to anaphylaxis. Prior exposures may be seen in those who are snake handlers or those who consume snake meat, both of which would lead to greater IgE sensitization to snake venom [11, 13-15]. In contrast, anaphylactoid reactions have a similar clinical presentation to anaphylaxis, but lack the IgE-mediated mechanism. It is postulated that mast cells and basophils may play bigger roles in anaphylactoid reactions, however the overall mechanism is still unclear [13]. With this in mind, it is plausible that anaphylactoid reactions may occur in individuals without a history of prior antigen exposure.

Our patient exhibited classic rapid onset symptoms of anaphylaxis including facial and oropharyngeal swelling, dyspnea, flushing, and vomiting. The right upper extremity did not exhibit significant swelling until several $\mathrm{h}$ after envenomation, well after the onset of life-threatening oropharyngeal swelling. The patient in this report had not had prior exposures to snake venom, suggesting that his rapid and severe oropharyngeal edema was more likely to be caused by an anaphylactoid reaction. Although rare, previous reports describe anaphylactoid symptoms after a reported first envenomation event with an extremity bite site [8-12]. However, symptoms resolved after administration after $\mathrm{CroFab}^{\circledR}$ or medication and did not require emergent airway management [9-12]. Two cases describe placement of emergent airways, however, one patient had previous exposure to rattlesnake antigens via ingestion of rattlesnake meat and the other was suspected to have sucked the venom from the bite site, thereby experiencing a localized oropharyngeal reaction $[8,11]$. In contrast, our patient denied all previous exposure to rattlesnakes. This was confirmed on subsequent interviews with both him and his family. Our report is unique in both the severity of the immediate oropharyngeal edema from the anaphylactoid reaction and the requirement of emergent surgical airway.
Notably, no rapid decrease in severity of oropharyngeal edema or other symptoms occurred upon rapid administration of $0.3 \mathrm{mg}$ epinephrine, $\mathrm{H} 2$ blocker, and methylprednisolone, contrasting with a previously case [10]. Although no second dose was given within 15 - $20 \mathrm{~min}$, an epinephrine infusion was begun within $1 \mathrm{~h}$ of envenomation. This delay may have contributed to the increased severity of symptoms. More likely, we believe that the lack of immediate $\mathrm{CroFab}^{\circledR}$ administration rendered the epinephrine administrations ineffective due to the continuing presence of circulating venom antigens. The lack of immediate $\mathrm{CroFab}^{\circledR}$ administration at the outside hospital was reportedly due to concern for anaphylaxis. Although $\mathrm{CroFab}^{\circledR}$ has been associated with severe anaphylaxis and serum sickness; we believe that the patient would not have developed a reaction since this generally requires prior antivenom exposure. We do not believe the patient's code event was triggered by administration of $\mathrm{CroFab}^{\circledR}$ upon arrival at our institution. Rather, this was likely due to systemic hypotension and worsening shock.

Our patient experienced prolonged respiratory failure requiring mechanical ventilator support until ten days postenvenomation, although facial and oropharyngeal edema decreased significantly by day four. Persistent respiratory failure has been reported following severe envenomation events [11, 16]. This was attributed to an intrinsic property of the Crotalus horridus venom in one case and the second due to persistent laryngeal edema $[11,16]$. We suspect the prolonged respiratory failure in our patient to be multifactorial resulting from potential direct effect of venom and aspiration pneumonia. However, without knowing the exact species of rattlesnake, this could not be explored further.

The immediate and delayed venom induced consumptive coagulopathy (VICC) experienced by our patient experienced is a known result of pit-viper envenomation due to the diverse mixture of proteins and metalloproteinases within rattlesnake venom [17-22]. The role of TEG in VICC has been previously described and we found it to be a useful adjunct in guiding the management of our patient's coagulopathy, as it obtains a full picture of the coagulation cascade via the utilization of whole blood analysis [23-25]. In addition to the various effects on the coagulation system, snake venom metalloproteases (SMVP) also play a role in disrupting the endothelial barrier integrity by widening intercellular junctions [26]. This phenomenon results in an increase in vascular permeability and hemoconcentration, which could have also contributed to the patient's respiratory failure via pulmonary edema and was likely demonstrated in the profound hemoconcentration noted on initial laboratory data.

\section{Conclusions}

Snake envenomation can be fatal in those who develop anaphylactic or anaphylactoid reactions with subsequent severe oropharyngeal edema. Anaphylactoid reactions do not require prior snake venom exposure, though the clinical severity may be venom dose dependent. Despite the differences in mechanism, both the presentation and treatment are identical. Delays 
in the administration of $\mathrm{CroFab}^{\circledR}$ may lead to increases in morbidity and increased severity of envenomation sequalae.

\section{Acknowledgments}

None to declare.

\section{Financial Disclosure}

None to declare.

\section{Conflict of Interest}

None to declare.

\section{Informed Consent}

Not applicable.

\section{Author Contributions}

PDD, LT, RJL, TEB, EDF involved in the study concept and design. PDD and LT contributed to the data acquisition and data analysis. PDD, LT, and RJL drafted the manuscript. PDD, LT, RJL, TEB, and EDF did the critical revision and approval of the manuscript.

\section{Data Availability}

The data supporting the findings of this study are available from the corresponding author upon reasonable request.

\section{References}

1. Ruha AM, Kleinschmidt KC, Greene S, Spyres MB, Brent J, Wax P, Padilla-Jones A, et al. The epidemiology, clinical course, and management of snakebites in the North American snakebite registry. J Med Toxicol. 2017;13(4):309-320.

2. Seifert SA, Boyer LV, Benson BE, Rogers JJ. AAPCC database characterization of native U.S. venomous snake exposures, 2001-2005. Clin Toxicol (Phila). 2009;47(4):327-335.

3. Jaramillo JD, Hakes NA, Tennakoon L, Spain D, Forrester JD. The "T's" of snakebite injury in the USA: fact or fiction? Trauma Surg Acute Care Open. 2019;4(1):e000374.

4. Toschlog EA, Bauer CR, Hall EL, Dart RC, Khatri V, Lavonas EJ. Surgical considerations in the management of pit viper snake envenomation. J Am Coll Surg. 2013;217(4):726-735.

5. Karlsson E. Chemistry of protein toxins in snake venoms.
Springer, Berlin, Heidelberg. 1979. p. 159-212.

6. Maduwage K, Buckley NA, de Silva HJ, Lalloo DG, Isbister GK. Snake antivenom for snake venom induced consumption coagulopathy. Cochrane Database Syst Rev. 2015;6:CD011428.

7. Brooks DE, Graeme KA, Ruha AM, Tanen DA. Respiratory compromise in patients with rattlesnake envenomation. J Emerg Med. 2002;23(4):329-332.

8. Hinze JD, Barker JA, Jones TR, Winn RE. Life-threatening upper airway edema caused by a distal rattlesnake bite. Ann Emerg Med. 2001;38(1):79-82.

9. Bebarta VS, Ferre RM, Peck M. Tracheal intubation prevented with administration of Fab antivenom after severe crotaline envenomation. J Emerg Med. 2010;39(1):e8183.

10. Nordt SP. Anaphylactoid reaction to rattlesnake envenomation. Vet Hum Toxicol. 2000;42(1):12.

11. Brooks DE, Graeme KA. Airway compromise after first rattlesnake envenomation. Wilderness Environ Med. 2004;15(3):188-193.

12. Rencher L, Schwartz J, Wilson A. An Anaphylactoid Reaction to Rattlesnake Envenomation in a Pediatric Patient. Pediatr Emerg Care. 2018;34(6):e109-e110.

13. Sampson HA, Munoz-Furlong A, Bock SA, Schmitt C, Bass R, Chowdhury BA, Decker WW, et al. Symposium on the definition and management of anaphylaxis: summary report. J Allergy Clin Immunol. 2005;115(3):584591.

14. Wadee AA, Rabson AR. Development of specific IgE antibodies after repeated exposure to snake venom. J Allergy Clin Immunol. 1987;80(5):695-698.

15. Ryan KC, Caravati EM. Life-threatening anaphylaxis following envenomation by two different species of Crotalidae. Journal of Wilderness Medicine. 1994;5(3):263-268.

16. Madey JJ, Price AB, Dobson JV, Stickler DE, McSwain SD. Facial diplegia, pharyngeal paralysis, and ophthalmoplegia after a timber rattlesnake envenomation. Pediatr Emerg Care. 2013;29(11):1213-1216.

17. Gutierrez JM, Escalante T, Rucavado A, Herrera C. Hemorrhage Caused by Snake Venom Metalloproteinases: A Journey of Discovery and Understanding. Toxins (Basel). 2016;8(4):93.

18. Lavonas EJ, Ruha AM, Banner W, Bebarta V, Bernstein JN, Bush SP, Kerns WP, 2nd, et al. Unified treatment algorithm for the management of crotaline snakebite in the United States: results of an evidence-informed consensus workshop. BMC Emerg Med. 2011;11:2.

19. Gold BS, Dart RC, Barish RA. Bites of venomous snakes. N Engl J Med. 2002;347(5):347-356.

20. Matsui T, Fujimura Y, Titani K. Snake venom proteases affecting hemostasis and thrombosis. Biochim Biophys Acta. 2000;1477(1-2):146-156.

21. Boyer LV, Seifert SA, Clark RF, McNally JT, Williams SR, Nordt SP, Walter FG, et al. Recurrent and persistent coagulopathy following pit viper envenomation. Arch Intern Med. 1999;159(7):706-710.

22. Bolliger D, Seeberger MD, Tanaka KA. Principles and practice of thromboelastography in clinical coagulation management and transfusion practice. Transfus Med Rev. 
2012;26(1):1-13.

23. Ganter MT, Hofer CK. Coagulation monitoring: current techniques and clinical use of viscoelastic point-of-care coagulation devices. Anesth Analg. 2008;106(5):13661375 .

24. Jeger V, Zimmermann H, Exadaktylos AK. Can RapidTEG accelerate the search for coagulopathies in the patient with multiple injuries? J Trauma. 2009;66(4):1253-
1257.

25. Cao D, Domanski K, Hodgman E, Cardenas C, Weinreich M, Hutto J, AbdelFattah KR, et al. Thromboelastometry analysis of severe North American pit viper-induced coagulopathy: A case report. Toxicon. 2018;151:29-33.

26. Gutierrez JM, Rucavado A. Snake venom metalloproteinases: their role in the pathogenesis of local tissue damage. Biochimie. 2000;82(9-10):841-850. 